
glyoxal profiles in the tropics: comparison with ship-based and in situ measurements

\author{
R. Volkamer et al.
}

Correspondence to: R. Volkamer (rainer.volkamer@colorado.edu) 


\section{Spatial scales}

The spatial scale sampled by CU AMAX-DOAS, defined as the sum of translational movement of the aircraft and the extinction length of photons, corresponds to about $35 \mathrm{~km}$ at ultraviolet wavelengths $(\mathrm{BrO})$, and $100 \mathrm{~km}$ at visible wavelengths (IO and glyoxal) in the FT. This volume of air is sampled near instantaneously from the aircraft, and closely resembles the spatial scales represented in atmospheric models ( 30 km for WRF; $\sim 15 \mathrm{~km}$ for RAQMS in RDF mode), satellite footprints $\left(\sim 13 \times 24 \mathrm{~km}^{2}\right.$ for OMI; $\sim 30 \times 60 \mathrm{~km}^{2}$ for SCIAMACHY; $\sim 40 \times 80 \mathrm{~km}^{2}$ for GOME-2), global models ( 60 km for GEOS-Chem; 110 km for CAM-Chem, WACCM, TM4ECPL; $300 \mathrm{~km}$ for RAQMS in forecast mode), spatial scales of Deep Convective Cloud features $(\sim 50-300 \mathrm{~km})$, and cirrus clouds (up to $1000 \mathrm{~km}$ ).

\section{Sensitivity study - tropospheric BrO}

We have conducted a sensitivity study to test the effect of a sharp gradient in BrO right above the tropopause (Salawitch et al., 2005) on the tropospheric BrO profile retrieved from limbobservations. The sensitivity study placed (unrealistic) 20pptv $\mathrm{BrO}$ in a layer between 17 and 18 $\mathrm{km}$ (we assume 4pptv between 14 and $17 \mathrm{~km}$ ). The profile inversion responds with less than 0.18 pptv additional $\mathrm{BrO}$ at $13.7 \mathrm{~km}$, which is insignificant within the inversion error bars. This confirms that our limb measurements are insensitive to stratospheric $\mathrm{BrO}$ even for extreme concentration gradients.

\section{BrO in the UTLS: Method context}

Direct-sun observations have been very successfully applied for profiling in the stratosphere. Some balloon-borne direct sunlight DOAS measurements have further reported tropospheric $\mathrm{BrO}$ levels in reasonable agreement with GOME at extra tropical latitudes (Fitzenberger et al., 2000; Van Roozendael et al., 2002). In the tropics, however, only very limited balloon-borne tropospheric BrO profiles are available (Dorf et al., 2008), and these profiles have detected about an order of magnitude less $\mathrm{BrO}(<1 \mathrm{pptv})$ in the troposphere than reported in this study, and previous column observations (Chance, 1998; Fitzenberger et al., 2000; Wagner et al., 2001; Richter et al., 2002; Van Roozendael et al., 2002; Salawitch et al., 2005; Hendrick et al., 2007; Theys et al., 2007; Coburn et al., 2011; Theys et al., 2011). The reasons for the difference are 
currently not clear, and could be attributable to atmospheric variability. A direct comparison of the information content for tropospheric $\mathrm{BrO}$ with our data is complicated by the fact that there is no mentioning about the DoF, or AVK in the peer-reviewed literature regarding BrO direct-sun observations (Pundt et al., 2002; Dorf et al., 2008). The one BrO profile inversion where this information is available is from Kiruna, Sweden (Dorf, M., 2005, Investigation of Inorganic Stratospheric Bromine using Balloon-Borne DOAS Measurements and Model Simulations, PhD thesis, University of Heidelberg, Germany). That profile showed $\sim 1$ DoF and AVK that peak around 0.1-0.2 in the troposphere (below $8 \mathrm{~km}$ ), and $12 \mathrm{DoF}$ in the stratosphere.

\section{Further sensitivity studies for IO}

Sensitivity tests on DOAS analysis settings showed a slight sensitivity of IO dSCDs towards the choice of polynomial degree ( $25 \%$ higher dSCDs for a $4^{\text {th }}$ order polynomial), but dSCDs were robust towards variations in the fit window. The starting wavelength of the fit window has been moved from 415 to $417 \mathrm{~nm}$, compared to Dix et al. (2013), because the HITRAN $2008 \mathrm{H}_{2} \mathrm{O}$ cross section has been replaced by a spectrum from HITEMP 2012 for the TORERO analysis. HITEMP includes more and stronger absorption lines between 410 and $438 \mathrm{~nm}$ and a more distinct absorption peak at $\sim 416.5 \mathrm{~nm}$ that is now excluded from the TORERO IO analysis. The results from a sensitivity test where the HITEMP $\mathrm{H}_{2} \mathrm{O}$ reference spectrum (Table 1) was substituted for a HITRAN $\mathrm{H}_{2} \mathrm{O}$ spectrum show $16 \%$ higher IO dSCDs compared to using the HITEMP spectrum (see Fig. S2), while the offset remained zero within error $\left(0.5 \pm 1.0 \times 10^{12}\right.$ molec $\mathrm{cm}^{-2}$ ). One further change compared to Dix at al., 2013 is that we are not fitting an additional residual cross section for IO anymore. Similar to (Schonhardt et al., 2008; Schonhardt et al., 2012), who present satellite IO measurements, we observe a systematic residual structure around $432 \mathrm{~nm}$ that is likely caused by an improperly corrected Fraunhofer line. While Schoenhardt et al. analyze IO from $416-430 \mathrm{~nm}$ to avoid this wavelength region, the analysis of all TORERO RFs has shown that this particular Fraunhofer line does not significantly affect our fit stability, nor RMS. Fitting an additional residual cross section is not necessary. 


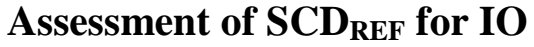

For IO the value of $\mathrm{SCD}_{\mathrm{REF}}$ is likely non-zero, and the reference geometries have limited flexibility to inherently minimize $\mathrm{SCD}_{\mathrm{REF}}$ for IO retrievals (see Sect. 2.3.1). This is different for IO than for the other gases, where $\mathrm{SCD}_{\mathrm{REF}}$ can be systematically minimized (e.g., zero for glyoxal), or kept constant within negligible error (e.g., $\mathrm{BrO}$ and $\mathrm{NO}_{2}$, see Sects. 3.2.2. and 4.2.). What is unique for IO is that the MBL EA0 geometry maximizes $\mathrm{SCD}_{\mathrm{REF}}$ due to the IO profile shape, and the MBL EA+90 leads to higher RMS for reasons that are currently unknown. We use an EA0 spectrum from RF12 for our analysis of both RF12 and RF17 flights; this does not present a fundamental problem, since the IO dSCDs from comparing EA0 references at different altitudes leads to a consistent offset that can be understood from the IO profile (Sect. 3.2.1.). However, this might complicate the correction of small amounts of IO that may reside in the lower stratosphere (Wennberg et al., 1997), as is illustrated by the shape of Box-AMFs in Fig. 6A. Assuming 0.1ppt IO between 17 and $45 \mathrm{~km}$, and no IO throughout the troposphere, we estimate that the $\mathrm{SCD}_{\mathrm{REF}}$ for RF12 is $0.66 \times 10^{12}$ molec $\mathrm{cm}^{-2}$ IO for EA0 at $14.5 \mathrm{~km}$, and 0.64 $\mathrm{x} 10^{12}$ molec $\mathrm{cm}^{-2}$ IO for EA+10 at $14.5 \mathrm{~km}$. Our limb-measurements at $14.5 \mathrm{~km}$ are essentially insensitive to such small amounts of stratospheric IO. Also, the insignificant change for different viewing geometries suggests that stratospheric IO, if present, cancels well (error few percent). We thus assume our measured IO dSCDs to be representative of IO SCDs, and use these in the inversion of IO, as discussed in Sect. 2.7.

\section{$\mathrm{H}_{2} \mathrm{O}$ spectral line parameters and glyoxal retrievals}

We prefer using the HITEMP $\mathrm{H}_{2} \mathrm{O}$ cross section over HITRAN in our final analysis, because laboratory tests to measure $\mathrm{H}_{2} \mathrm{O}$ absorption spectra using CE-DOAS at blue wavelengths at $\mathrm{CU}$ Boulder more closely resemble the HITEMP than the HITRAN spectra (Coburn et al., 2014). The most prominent unaccounted $\mathrm{H}_{2} \mathrm{O}$ features were observed between 441 and $447 \mathrm{~nm}$, and the strongest peak is near $442 \mathrm{~nm}$. All of these bands are shifted and well separated from the strongest glyoxal bands near $455 \mathrm{~nm} . \mathrm{H}_{2} \mathrm{O}$ features in the range of 450 to $458 \mathrm{~nm}$ are $10-20$ times weaker than the $442 \mathrm{~nm}$ peak, and unaccounted $\mathrm{H}_{2} \mathrm{O}$ features in this spectral range could have

optical densities on the order of $\sim 1-210^{-4}$ for $\mathrm{H}_{2} \mathrm{O}$ SCDs of $7.3 \times 10^{23}$ molec $\mathrm{cm}^{-2}$. Our laboratory 
measurements confirm that high-resolution water cross-section measurements are desirable. They also suggest that the quality of water correction is best indicated near $442 \mathrm{~nm}$.

Figure S2 shows dSCDs evaluated using identical analysis settings (Table 1), but using either a HITEMP (Rothman et al., 2010) or HITRAN (Rothman et al., 2013) $\mathrm{H}_{2} \mathrm{O}$ cross section spectrum for analysis of RF17. The difference in the glyoxal dSCD is about 10\%, and no significant offset is observed $\left(<0.1 \pm 0.3 \times 10^{14}\right.$ molec $\left.\mathrm{cm}^{-2}\right)$. We see no noticeable difference (error within $\left.2 \%\right)$ if a water reference, or water residual is used during spectral fitting of glyoxal dSCDs (Sinreich et al., 2010). The glyoxal dSCDs further did not change significantly (error within 5\%) whether the residual is included or not (Fig. S2). With either HITEMP or HITRAN cross-sections the fit finds a consistent solution if the residual is added to the water cross-section (difference between slopes of 1.06 and 1.04, see Fig. S2). As an extreme test, if the HITEMP residuum is fitted with the HITRAN cross-section, the slope in Fig. S2 increases to 1.13, but the offset remains negligible (not shown). Sensitivity tests showed no significant correlation between glyoxal and $\mathrm{H}_{2} \mathrm{O}$ dSCDs (correlation coefficient $<0.05$, for $3^{\text {rd }}$ to $5^{\text {th }}$ order polynomial). The $5^{\text {th }}$ order polynomial for AMAX showed the lowest degree of correlation, and is the polynomial order chosen for our AMAX analysis.

Recently, Thalman et al. (2014a) tested the sensitivity of glyoxal retrievals towards water under simulated atmospheric conditions, as part of an intercomparison campaign where CE-DOAS and six other techniques to measure glyoxal (methylglyoxal and $\mathrm{NO}_{2}$ ) participated. We did not find any noticeable sensitivity for glyoxal SCDs in DOAS retrievals of spectra recorded in dry and moist air (tested up to 58\% RH). The glyoxal concentrations were generally higher in that study ( 200 pptv), but the CE-DOAS sensitivity was suitable to assess changes in glyoxal of atmospheric relevance. Recent EC flux measurements of water and glyoxal during the TORERO cruise further showed no evidence for an obvious sensitivity at $\sim 30 \mathrm{pptv}$ glyoxal at $80 \% \mathrm{RH}$ (Coburn et al., 2014). While the water fluxes were consistently positive (indicating evaporation), the glyoxal fluxes were positive at night, and more positive in certain parts of the ocean, but negative during most of the daytime. The $\mathrm{H}_{2} \mathrm{O}$ and glyoxal EC fluxes showed no evidence of a correlation, see Sect. 3.3.3 in Coburn et al. (2014). 


\section{Note on $\mathrm{H}_{2} \mathrm{O}$ measurements}

The rather weak $\mathrm{H}_{2} \mathrm{O}$ cross-section at $442 \mathrm{~nm}$ has good signal-to-noise to detect water below 9 $\mathrm{km}$, but dSCDs are close to the noise level at higher altitudes. As indicated in Fig. 7, the AMAX$\mathrm{H}_{2} \mathrm{O}$ AVKs peak near unity at and below $9 \mathrm{~km}$, and rapidly decrease at higher altitudes. There is room to improve signal-to-noise for $\mathrm{AMAX}-\mathrm{H}_{2} \mathrm{O}$, probably by a factor $10-20$, if stronger $\mathrm{H}_{2} \mathrm{O}$ cross-sections at longer wavelengths are used (e.g., $510 \mathrm{~nm}$ ), which has the further benefit of longer absorption paths. No attempts have been made to optimize the $\mathrm{AMAX}-\mathrm{H}_{2} \mathrm{O}$ retrievals in this respect, and we limit the discussion of $\mathrm{AMAX}-\mathrm{H}_{2} \mathrm{O}$ profiles to altitudes below $9 \mathrm{~km}$; data at higher altitudes should be viewed as qualitative. 

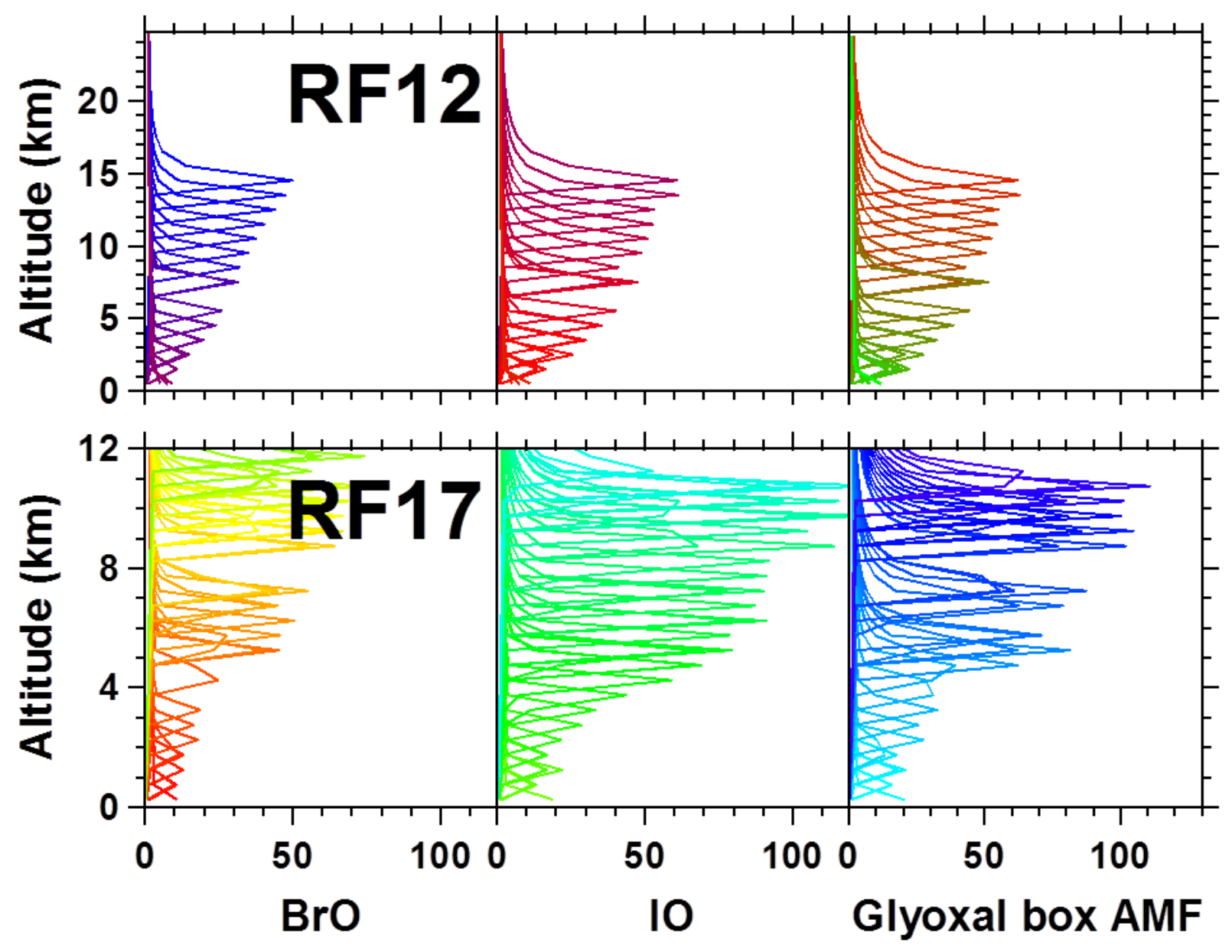

Figure S1: Box-AMFs calculated at 350nm (BrO), 428nm (IO) and 450nm (Glyoxal) using the respective aerosol profiles for the RF12 and RF17 profile case studies. 

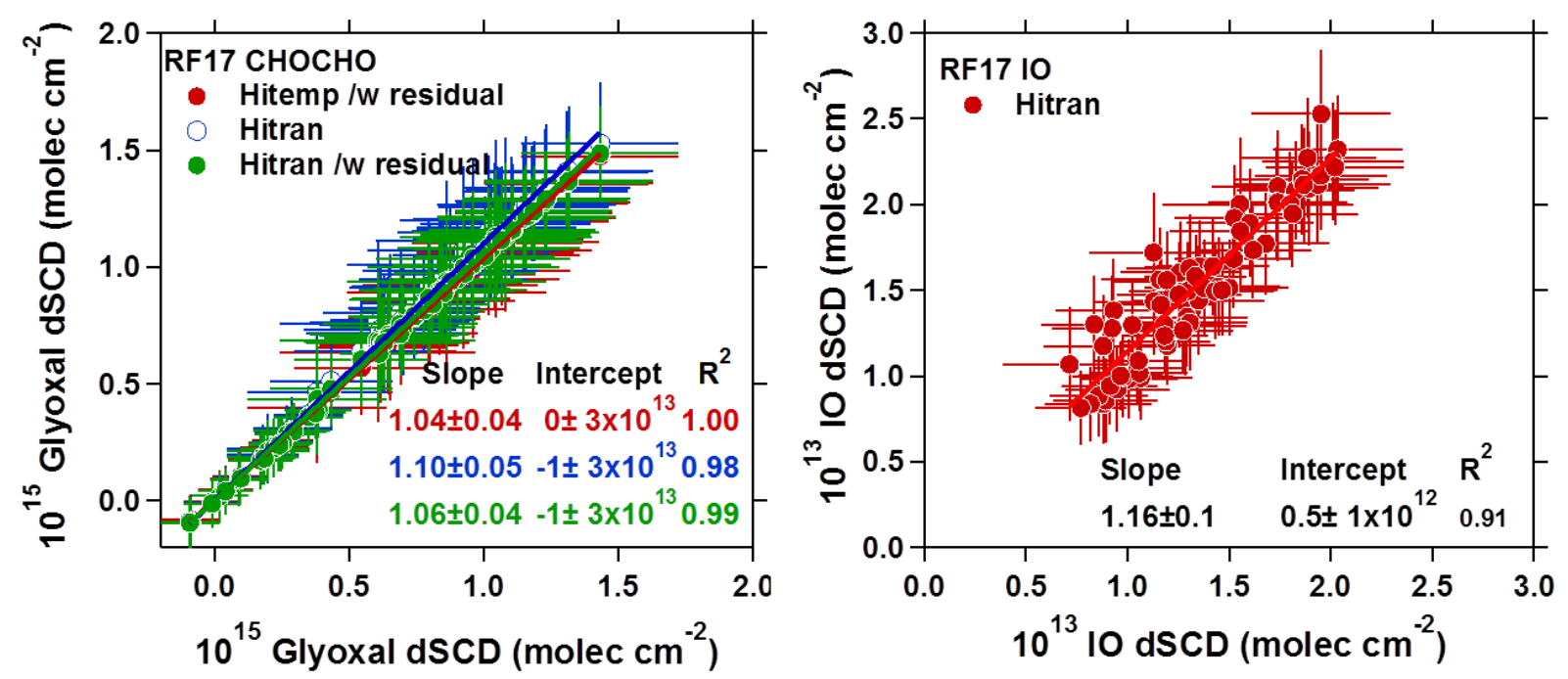

Figure S2: Sensitivity studies to explore changes in glyoxal and IO dSCDs towards uncertainties in the water cross-section. 